\title{
Civic infrastructure and the appropriation of the corporate smart
}

\section{city}

Sung-Yueh Perng and Sophia Maalsen

Tunghai University, Taiwan and University of Sydney, Australia

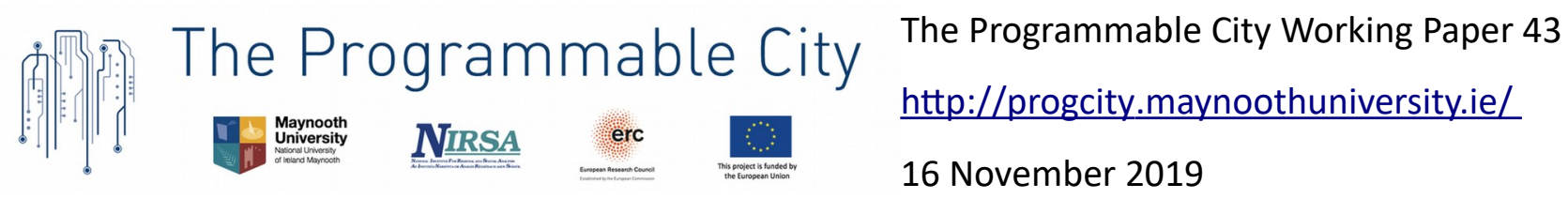

This is an Accepted Manuscript of an article published by Taylor \& Francis in Annals of the American Association of Geographers, available online:

https://www.tandfonline.com/doi/full/10.1080/24694452.2019.1674629.

\begin{abstract}
Concerns have been raised regarding smart city innovations leading to, or consolidating, technocratic urban governance and the tokenization of citizens. However, less research has explored how we make sense of ongoing appropriation of the resources, skills, and expertise of corporate smart cities and what this means for future cities. In this paper, we examine the summoning of political subjectivity through the practices of retrofitting, repurposing, and reinvigorating. We consider them as "civic infrastructure" to sensitize the infrastructural acts and conventions that are assembled for exploring inclusive and participatory ways of shaping urban futures. These practices, illustrated by examples in Adelaide, Dublin, and Boston, focus on capabilities not only to write code, access data or design prototype, but also to devise diverse sociotechnical arrangements and power relations to disobey, question, and dissent from technocratic visions and practices. The paper concludes by suggesting further examination of the summoning of political subjectivity from within established institutions to widen dissent and appropriation of the corporate smart city.
\end{abstract}

\section{Keywords}

Citizen, infrastructure, political subjectivity, smart city, urban future. 


\section{Introduction}

In this paper we consider infrastructure for smart places by rethinking smart city deployment and appropriation. Smart city developments have gone through various iterations, transitioning from corporate discourses to the deployment of digital infrastructure to improve urban living, but have caused considerable concerns (e.g. Marvin, Luque-Ayala, and McFarlane 2016; McLean, Bulkeley, and Crang 2016). Among them, citizen participation is one of the most contentious issues. In early smart city masterplans, citizens were often absent, and the city a "sanitized, orderly and programmable smart polis" (Datta 2015, 53). When present in smart city visions, citizens are subjugated to surveillant infrastructure and monitored constantly to pre-empt any threats to the safety of the city (Vanolo 2016). Furthermore, the terms of participation are also questionable. The "co-creation" and "citizen-centric" approaches to smart city developments, as Cowley, Joss, and Dayot (2018) contend, do not amount to the "public city" because they are shaped by corporate conceptions of citizens as consumers and entrepreneurs who do not prioritize or engage with public interests. Accordingly, citizen participation in smart cities tends to be "post-political", focusing on "instrumental rather than normative or political" engagements, creating technological solutions but failing to "challenge or replace the fundamental political rationalities shaping an issue or plan" (Cardullo and Kitchin 2017, 10).

The corporate smart city can be challenged in different ways. On the one hand, Datta (2018) demonstrates the breaches that the "chatur citizen" performs to resist the subjecthood prescribed by the state and corporations. Also, digital civics can be organized to challenge social and political hierarchies, devising radical interventions beyond digital spaces and resisting technocratic understandings of and responses to urban problems (Shelton, 2018). 
On the other, the ways these small-scale interventions are considered in relation to the corporate smart city can also be reframed. They can be considered as humanizing smartness and "using technology to realize progressive ideas, rather than see[ing] the technology as progressive in and of itself" (Hollands 2015, 63; de Lange and de Waal 2013). As smart cities develop, we see an emerging number of interventions where smart technologies come face-to-face with the messiness and complexities of cities, and the promise of a smart utopia is re-contextualized to the site. As Karvonen, Cugurullo, and Caprotti $(2018,4)$ note, corporations have been joined by multiple stakeholders including "local governments, utility providers, small and medium enterprises, and civil society organizations" in the implementation of smart cities. This means that smart can be reinterpreted, co-opted, and appropriated as it materializes in the actually existing city. In Australia, for example, the roll out of smart cities has provided interesting commentary on the corporate smart city, materializing instead through savvy local governance that remains vendor agnostic, protects their smart assets, and demands that technology products meet their contextual and citizen needs (Dowling, McGuirk, and Maalsen 2018).

In what sense the corporate smart city might be challenged remains a critical issue. The paper contributes to this ongoing work by proposing three infrastructural practices to consider if and how political subjectivity can be invoked to appropriate smart infrastructure and cities for civic purposes. We argue that exploring the practices of "retrofitting", "repurposing", and "reinvigorating" provides a useful way to consider the rupture to smart city innovation and governance and the appropriation of their techniques and infrastructure. Our discussion proceeds by charting the tension between citizenship and the ongoing privatization of infrastructure. It then draws upon Isin and Ruppert (2015) and infrastructure studies to suggest how "retrofitting", "repurposing", and "reinvigorating" can build civic infrastructure to appropriate the corporate 
smart city. Three cases are used to illustrate how political subjectivity might be invoked and the effects that these practices might generate. These three practices reveal possibilities of appropriation and imaginings of a more inclusive smart city.

\section{Infrastructure and citizen participation}

While infrastructure is commonly thought of as a political, technological, and discursive technology of state governance (Kooy and Bakker 2008), the increasing privatization of infrastructure has led to concerns over the subjects and exercise of citizenship. The unbundling of infrastructural networks has resulted in "premium networked space" where socially and economically privileged citizens are preferentially provided with accesses to public services (Graham and Marvin 2001). In this transition, the figure of citizens as the customer of state has double exclusionary effects. As infrastructure is turned into a marketplace, "empowering" technologies and services become reserved for the customers who can afford the access (Viitanen and Kingston 2014). Meanwhile, the socially disadvantaged are required to be "fit for market" through building their "calculating subjectivity" and becoming fee-paying, economically "responsible" citizens, before any access to basic public services is granted (von Schnitzler 2008). Further, while governments and corporations adopt "deliberative rhetoric" to promote the scope of public participation in infrastructure planning, citizens construed as "customers" have limited "decisional influences" on the outcome (Cotton and Devine 2012).

However, the citizen subject can be contested in the assembling of alternative discourses, subjectivity, and resources to reconfigure infrastructure. While infrastructure can extend state and corporate control over people and places, Meehan (2014) and Anand (2015) show that such 
control is leaky and its circumvention is inevitable where alternative assemblages of citizen subjects, discourses, norms, and tools constitutes an uneven spatiality of power. As Roy (2009) contends, power relations within regimes of "civic governmentality" are far from uni-directional and clear-cut. Instead, they comprise citizen subjects and state agencies both equally capable of exercising state-rule or civic identity.

Further, the conflicting subjects and exercise of citizenship are inseparable from the situated experiences and knowledges of infrastructure. Davies et al (2012) problematize discursive rationality as the sole basis of participating in deliberation processes. Instead, they highlight that the multiple, affective, embodied, and practical rationalities in everyday life are crucial resources for establishing participatory and inclusive engagement processes for infrastructure development. At issue here then, is the situatedness of political subjectivity, which according to Coward (2012) is crucial to understand competing configurations of belonging, exclusion, and ways of enacting togetherness through material engagement with infrastructure and spatially distributed others, both close and distant.

\section{Civic infrastructure: Challenging the corporate smart city}

The diverse relations between infrastructure, citizen subjects and the exercise of citizenship as observed above are captured by Isin and Ruppert (2015). They further argue for understanding citizenship through the enactment of legal, performative and imaginative acts. Rather than perceiving citizens as already formed, they contend that citizenship is a dynamic and contested figure of politics, situated in "a composite of multiple forces, identifications, affiliations, and associations" $(2015,21)$. Citizen subjects are brought into being through acts and conventions of 
subjectivation, the "summoning" and "taking up" of political subjectivity as an entanglement of different power relations, including disobedience, submission, and subversion. Crucially, these acts, conventions, and entangled power relations produce possibilities to discern, question, and act in dissent to authority in enacting rights.

Subsequent examinations of "smart citizens" focus on questions concerning how political subjectivity can be taken up and what acts of citizenship can be performed? For Vanolo (2016), the political subject is limited because only few people possess appropriate technical expertise, access to technology and thus an influential voice to exercise their rights. But for Datta $(2018,414-6)$, the discursive formation of the "chatur citizen" at odds with Indian smart city policies is a speech act that draws from local governance and urban everyday reality to redefine smart citizens. The different interpretations of the possibilities of "smart citizenship" above, alongside the contradictions in smart cities observed in Karvonen, Cugurullo, and Caprotti (2018), remind that the taking up of political subjectivity is a process where "composites of multiple subjectivities are likely to emerge from different situations and relations" (Vanolo 2016, 35). This echoes Gabrys' (2016) argument that citizenship is a process of becoming that is constituted by acts of sensing and other digital practices, complicating how the relations between citizens, technologies, cities, and environments are formed.

Isin and Ruppert's (2015) work informs our understanding of civic infrastructure as summoning political subjectivity and creating openings for new infrastructural imaginaries and arrangements to shape alternative smart cities and places. Civic infrastructure comprises sociotechnical practices that call upon political subjectivity to problematize the corporate smart city and bring into being exercises of judgment and acts of dissent to disrupt technocratic practices and visions of 
innovation. We highlight three practices that could disrupt corporate smart infrastructure and create openings in different ways: retrofitting, repurposing and reinvigorating. Retrofitting enacts political subjectivity by indicating the failures of smart infrastructure and mobilizing care and collaboration to repair them. Repurposing builds political subjectivity by discerning and experimenting infrastructural arrangements and effects that transgresses the corporate smart city. Reinvigorating subverts technocratic visions of smart cities by exploring infrastructural arrangements to place the politics of participation at the forefront of innovation. Taken together, these practices resignify participation, innovation, and governance by translating inclusive and participatory visions into practices and protocols for any city and place to become smart. We illustrate these practices with three case studies conducted in three different cities. While these practices are observed across the cities, we present each practice in relation to a case study for more focused discussion.

\section{Retrofitting}

How can infrastructural arrangements for the corporate smart city be retrofitted and in what ways can political subjectivity be summoned for this purpose? This question follows the argument that infrastructure, and the control it implements, can become leaky (Meehan 2014; Roy 2009), and further explores how the insufficiency of corporate infrastructure can be revealed and how openings for alternative arrangements can be explored. The case of Adelaide illustrates how such a possibility might materialize.

Adelaide, South Australia, is a Cisco Lighthouse city and one of Australia's early adopters of smart city approaches. A growing cooperation with the city council has seen Adelaide's smart city initiatives taking a multi-vendor approach to provide technological solutions that best benefit the 
city. These initiatives include, among others, increased connectivity ("Adelaide Gig City"), reduced electricity consumption (“Follow Me" responsive LED lighting system), and enhanced citizen innovation (Smart City Studio) (Maalsen, Burgoyne, and Tomitsch 2018).

The installation of LoRaWAN, a digital wireless network, shows how retrofitting provides an opportunity to expand smart Adelaide. The network is not only an economical choice for the City but also particularly applicable to projects attuned to community needs:

LoRaWAN is cost-effective. It's the infrastructure that might enable a range of different scientific projects and experiments, but initiatives that have more of a community focus (Smart City Studio Manager, 17 August 2016).

Indeed, the service-user publicness (Cowley, Joss, and Dayot 2017) and the figure of citizens as state customers (Viitanen and Kingston 2014) are salient in the Manager's discussion. However, retrofitting smart infrastructure can be observed as rearranging infrastructure for redefining for whom innovation is pursued. The Studio itself converts a reused office space in a busy part of the State Department of Premier and Cabinet building to attract the attention from the public and public officials and invite innovative ideas by showcasing existing smart technologies there. The retrofitting of space attests to the Studio's shift away from consolidating governmental and corporate ownership of innovation. Instead, it attempts to enable initiatives that are collaborative and community-building by linking local people with innovative ideas to government resources and infrastructure. The proposal of a community LoRaWAN in a meetup 
organized by the Studio is an example of the retrofitting of computational networks into the urban fabric. The Manager tells a story of one enterprising member of the public who,

is desperately keen to get access to this [LoRaWAN] because he wants to install sensors in all the possum boxes and the bird boxes in the Adelaide park plans. At the moment there's no mechanism to understand whether or not these boxes are being used and in what way. So, with the rollout that is relatively costeffective, as opposed to someone coming, walking around with a clipboard, and hoping that the possum is there, and there on the right day. I think that type of data can help to transform the ways in which we support our native animals and the parklands. It's probably quite low range stuff, but it's just transformational... (Smart City Studio Manager, 17 August 2016).

Here, while retrofitting LoRaWAN has not been in a directly confrontational relation against corporate smart infrastructure, the practice creates space for looking into certain aspects of urban life that have not been included in Adelaide's smart city agenda. Government and corporate resources have been appropriated for developing ideas and initiatives to transfer ownership to local communities. The reworking of existing infrastructural arrangements in the way discussed above produces retrofitting's ambiguity where the "futurological orientation" of infrastructure rests upon the uncertain effectiveness of its current configuration (Howe et al 2016). The ambiguity requires creativity and social collaboration to continue retrofitting existing technological and government infrastructure to respond to issues that are otherwise unseen (Silver 2014). 
Using the case of Adelaide to consider retrofitting illustrates the summoning of political subjectivity by enacting infrastructural arrangements that are open, rather than prescriptive. Retrofitting does so by creating a liminal space in smart city infrastructure, as Zandbergen (2017) also observes in an Internet-of-Things meetup in Amsterdam, to align interests and demands that are not foreseen in the initial set-up of the infrastructure. Retrofitting smart infrastructure in this way presents the possibility of disobeying existing infrastructural logic and effects as seen in the corporate smart city, adjusting arrangements to meet oncoming demands, and responding to issues that might otherwise remain unseen. That is, retrofitting invokes subversion and demands submission to participate in sustaining its reconfiguration of smart infrastructure through attempts of accessing government and technological infrastructure for community-led innovation. It expands the visions and practices of smart infrastructure beyond consolidating control and ownership of innovation and towards caring for the issues and lives that become obscured in earlier iterations of emerging infrastructure networks.

However, as Mattern (2016) notes, care and caring for urban infrastructure are political, which has implications for who provide and receive care and how care is delivered. This resonates with Cardullo and Kitchin (2017)'s concern that many "citizen-focused" smart city projects are conceived in paternalistic ways where the purpose of innovation, the eligibility to innovate, and the terms on which people are engaged in innovation activities are predetermined. We turn to these questions in the two cases below.

Repurposing

"Open innovation" and "living labs" are increasingly popular "citizen-focused" innovation approaches adopted for developing smart infrastructure. These approaches aim to produce 
innovation reflective of citizen's needs. However, in effect, they lead to the intensification of neoliberal governance (Bulkeley and Castán Broto 2013) and reductionist governance practices that foreclose the exploration of issues likely to emerge from taking a "citizen-centric" approach (Joss, Cook, and Dayot 2017). Instead of perpetuating such effects, we consider repurposing and its potential to challenge rather than consolidate existing governance practices. We discuss Dublin City Council (DCC) Beta to consider how public officials subject themselves to repurpose corporate innovation techniques to experiment and improve governance practices.

DCC Beta "is a live mechanism for imagining, testing, and implementing ways to improve the experience of life in the Capital". ${ }^{1}$ Since 2012, DCC Beta has conducted many trials to this effect, such as Equinox Cycle Parking (using on-street parking space for temporary bicycle hangars during summer) and Driving Data (understanding car traffic by purposes of travel and cohorts of drivers).

However, it is the repurposing of design practices, not the success of individual projects, that is important. DCC Beta incorporates design practices commonly used at "open innovation" events for citizen engagement, including post-it notes for public brainstorming or props for encouraging participant interactions. Crucially, these corporate design practices are repurposed to experiment alternative sociotechnical practices of governance. During repurposing, the ways in which municipality employees collaborate with citizens and implement citizen-suggested changes are put under the microscope. DCC Beta develops a "middle out" approach, which involves DCC on-theground staff taking more responsibility in prototype testing. This approach recognizes that simply attracting ideas and suggestions from citizens is insufficient to change governance practices because any suggestion "eventually has to go to probably a member of the local authority wherever in the world they are" (DCC Beta coordinator, 23 November 2015). Accordingly, the 
municipality has to build capacity so that ideas can be acted upon rather than treated as a token of engagement:

often that assumes that the staff member that are actually paid by those citizens haven't thought of [the ideas]. Often, they have, but they just don't have a method to actually do it themselves.

Iterative design, a common software and service development approach highlighting continuous testing and refinement, has been incorporated into the middle out approach to address the lack of a method. The approach emphasizes starting with small projects and being transparent about the selection, progress, evaluation, and future iterations. This provides opportunities for overseeing and improving the trials and DCC Beta itself.

Accordingly, with the middle out approach, DCC Beta repurposes corporate design practices to experiment how governance practices can implement proposals of change by citizens. DCC Beta does not seek to reduce uncertainty in governance through innovation as observed in many urban living labs. Instead, it exposes issues that arise from transforming citizens from passive consumers to active contributors and in understanding that possible solutions require continuous revision. Therefore, repurposing here no longer concerns policy change for local economic growth and entrepreneurial governance (Lauermann 2018). Rather, the case of DCC Beta illustrates the potentiality of repurposing in reconfiguring infrastructural arrangements to produce effects not initially conceived (Boyce 2016; Rossiter 2017). It does so by "hold[ing] the social and material in suspension" and experimenting with prototypes, not in search for closure or full solutions but for 
continuous "forking and enabling novel extensions" to re-inscribe the right to reassemble infrastructure (Corsín Jiménez 2014).

Accordingly, repurposing ruptures and resignifies smart city governance. The norms of smart city governance can be suspended by discursive and material imaginations around the "chatur" citizen" that redefine state and citizen relation (Datta 2018). The case of DCC Beta illustrates how existing city governance might be suspended and re-enacted through repurposing corporate innovation techniques to devise infrastructural arrangements to redraw governance practices. Political subjectivity summoned by repurposing creates opportunities for questioning how current urban governance works and fails, a refusal to consolidate the existing political economy of urban innovation, and arrangements for trials and change within governments. In doing so, reconfigurations of governance practices rupture the citizen-as-consumer, and instead create openings by enacting protocols and mechanisms to implement citizens' proposals for shaping future cities.

\section{Reinvigorating}

The other questions raised above are concerned with the eligibility for and the terms of participation in innovation - who gets to innovate and what is involved? Smart city projects are often criticized for the lack of inclusive protocols to engage citizens who are only data points or tokens in innovation and knowledge generation processes (Kitchin, Cardullo, and Di Feliciantonio 2019). The case of Boston's Public Lab illustrates how sensing can be resignified as acts of inclusive witnessing performed by an activist organization for enacting practices and protocols to engage diverse participants in sensing and innovation activities. 
Public Lab started as an activist citizen sensing initiative in the aftermath of the BP oil spill in the Gulf of Mexico in 2010 and has since grown into a community of local and global contributors. It conducts sensing projects with an aim to make visible the previously invisible people, perspectives, and their environmental concerns:

Public Lab is a community where you can learn how to investigate environmental concerns. Using inexpensive DIY techniques, we seek to change how people see the world in environmental, social, and political terms ${ }^{2}$

The use of "inexpensive DIY techniques" addresses the concerns of access and technical expertise required for citizen participation in smart city critiques (c.f. Vanolo 2016). Further, the protocols and practices Public Lab establishes respond to known concerns regarding the discouraging experiences for female and minority participants with open source or crowdsourcing communities (e.g. Ford and Wajcman 2017). Public Lab establishes various conventions to address the issue, such as increasing female staff and incorporating diversity statements when recruiting new staff to encourage applicants from different backgrounds. These measures produce ripple effects. The diversity within staff "amplifies into the broader organizers group and the much larger community as well" (Public Lab main coordinator, 15 April 2016), and in projects focusing on environmental pollution there is a relatively larger number of participants from diverse backgrounds.

Public Lab also devises collective decision-making and careful communication practices to ensure that people "interact with one another in respectful and meaningful ways" and communicate "in a less jargony way or a way that is kinder" (quotes here and below, Public Lab main coordinator, 15 April 2016). For this purpose, projects only involving Public Lab members are utilized to simulate 
how they would work with external partners by "deal[ing] with what needs to happen internally ... [a]nd then you think outwards", building "early agreements in our group around how we would work together, how we would interact with different projects, what our model was going to look like".

Practices and protocols that were initially unforeseen have also been established to recognize the importance of otherwise invisible processes of knowledge generation. Researchers in formal institutions are increasingly using the sensing tools Public Lab builds, and also "contribute information [about the tools] once they have figured something out or haven't figured it out" in the wiki pages for relevant tools or projects. The emergent practice of "people ... post[ing] about failures or things that didn't go right in the scientific process, ... teaches people equally as much". This sharing practice becomes a protocol within the Public Lab community through the implementation of the CERN Open Hardware License, where participants are expected to report back on their use or modification of the tools developed by Public Lab. This then becomes a convention of "do what you will ... but share it back to the community because that is how we learn together". Through these practices and protocols, what is recognized and enacted is doing sciences as they are situated in particular places, tools, and people, rather than making these people and processes invisible in the pursuit of innovation.

Accordingly, Public Lab demonstrates the possibilities for sensing "not to be governed quite so much - or in that way" (Gabrys 2016, 190). It illustrates how to reinvigorate sensing with a set of practices and protocols that foreground the diverse people and processes involved in innovation and knowledge generation. Public Lab devises social, organizational, and technical arrangements to establish an infrastructure that sustains the removal of invisible and implicit assumptions that 
prefigure the absence of diverse knowledge, perspectives, expertise, and experiences. These measures disrupt unequal power relations and social selectiveness in participant's experiences with infrastructural arrangements (c.f. Davies et al 2012). Therefore, reinvigorating as demonstrated in the case of Public Lab energizes the "speculative constructions and additional urban potentialities" (Gabrys 2016, 244) in ways that generate future possibilities and capacities to reroute power relations.

Reinvigorating thus summons political subjectivity that enacts inclusive innovation by establishing appropriate protocols and practices. It exercises careful resignification of sensing by underlining and responding to the epistemically, socially, and politically conflicting relations in the process. Therefore, far from being obedient, reinvigorating creates openings for dissenting from technocratic visions of innovation by exploring infrastructural arrangements that place the politics of participation at the forefront. The arrangements Public Lab establish thus act as proclamations and protocols that invoke active, open and inclusive undertaking of sensing, sciences and innovation that can better guide future shaping of cities and places.

\section{Conclusion}

Smart city infrastructure has rightfully been critiqued for its privileging of technology, corporations, and "experts" at the expense of citizens. However, the citizen subjects of smart cities are not passive. In this paper, we argue that political subjectivity can be summoned in and through the practices of retrofitting, repurposing, and reinvigorating to establish protocols and practices to include these citizen subjects in shaping future cities. These practices reveal the possibilities of corporate infrastructure to be made accessible, expandable and changeable, contesting corporate 
co-optation of the city and appropriating its technologies, resources, and practices. Furthermore, as these practices are undertaken, political subjectivity enacts different power relations that problematize the corporate smart city, as well as devising infrastructural acts and conventions that resignify innovation, governance, and participation. Accordingly, these practices offer a combination of imaginaries, explorations, and protocols for experimenting and establishing open and participatory ways of shaping future cities and places.

Our discussion raises further questions regarding the place and infrastructure for political subjectivity. The selection of a sensing network project, a government initiative, and a "lab" to illustrate infrastructural acts and conventions is intentional. These are unlikely "places" to find civic actions and for political subjectivity to emerge. However, they deserve greater attention. Taking seriously that political subjectivity is situated in entangled forces, affiliations and associations, these places are not devoid of any opportunity to create openings. The place and infrastructure for political subjects can embrace such complexity.

We recognize, as we have elsewhere (Maalsen and Perng 2017), that the ability to appropriate infrastructure is unevenly experienced and we must continue to critically assess who the smart city is being appropriated by and for whom. Nevertheless, while we can question whether the examples above generated significant change on the city, they are illustrative of the potential of the civic appropriation of corporate infrastructure to build a more inclusive smart city of the future. This is where the value of the framework we have sketched here resides. What would the smart city look like if it was reconfigured by the retrofitting, repurposing and reinvigorating of civic infrastructure? 


\section{Notes}

1. Quotes about DCC Beta here and below from https:dccbeta.ie/about [11 November 2018]

2. Quoted from https://publiclab.org/ [accessed 11 November 2018]

\section{Acknowledgements}

We would like to thank the reviewers for their thoughtful comments on this paper. The research and subsequent work would not be possible without the encouragement from our colleagues who have contributed to and supported The Programmable City project funded by an ERC Advanced Investigator Award to Rob Kitchin (ERC-2012-AdG-323636-SOFTCITY). Some of the Australian data was gathered for a scoping project funded by Telstra on smart cities in Australia. 


\section{References}

Anand, N. 2015. "Leaky States: Water Audits, Ignorance, and the Politics of Infrastructure". Public Culture 27 (2 (76)): 305-30. doi:10.1215/08992363-2841880.

Boyce, A. M. 2016. Outbreaks and the Management of "Second-Order Friction": Repurposing Materials and Data from the Health Care and Food Systems for Public Health Surveillance. Science \& Technology Studies 29 (1): 52-69.

Bulkeley, H., and V. Castán Broto. 2013. Government by experiment? Global cities and the governing of climate change. Transactions of the Institute of British Geographers 38 (3): 361-75. doi:10.1111/i.1475-5661.2012.00535.x

Cardullo, P., and R. Kitchin. 2017. Being a "Citizen" in the Smart City: Up and down the Scaffold of Smart Citizen Participation. GeoJournal, May. doi:10.1007/s10708-018-9845-8.

Corsín Jiménez, A. 2014. The Prototype: More than Many and Less than One. Journal of Cultural Economy 7 (4): 381-98. doi:10.1080/17530350.2013.858059.

Cotton, M, and P. Devine-Wright. 2012. "Making Electricity Networks "Visible": Industry Actor Representations of "Publics" and Public Engagement in Infrastructure Planning". Public Understanding of Science 21 (1): 17-35. doi:10.1177/0963662510362658.

Coward, M. 2012. "Between Us in the City: Materiality, Subjectivity, and Community in the Era of Global Urbanization". Environment and Planning D: Society and Space 30 (3): 468-81. doi:10.1068/d21010.

Cowley, R., S. Joss, and Y. Dayot. 2018. The Smart City and Its Publics: Insights from across Six UK Cities. Urban Research \& Practice 11 (1): 53-77. doi:10.1080/17535069.2017.1293150.

Datta, A. 2018. "The Digital Turn in Postcolonial Urbanism: Smart Citizenship in the Making of India"s 100 Smart Cities". Transactions of the Institute of British Geographers 43 (3): 40519. doi:10.1111/tran.12225 
- - 2015. A 100 Smart Cities, a 100 Utopias. Dialogues in Human Geography 5 (1): 49-53. doi:10.1177/2043820614565750.

Davies, S. R., C. Selin, G. Gano, and A. G. Pereira. 2012. “Citizen Engagement and Urban Change: Three Case Studies of Material Deliberation". Cities 29 (6): 351-57. doi:10.1016/j.cities.2011.11.012.

Dowling, R., P. McGuirk, and S. Maalsen. 2018. Realising Smart Cities: Partnerships and Economic Development in the Emergence and Practices of Smart in Newcastle, Australia. In Inside Smart Cities: Place, Politics and Urban Innovation, ed. A. Karvonen, F. Cugurullo, and F. Caprotti, 15-29. London, UK: Routledge.

Ford, H., and J. Wajcman. 2017. "Anyone Can Edit", Not Everyone Does: Wikipedia"s Infrastructure and the Gender Gap. Social Studies of Science 47 (4): 511-27. doi:10.1177/0306312717692172.

Gabrys, J. 2016. Program Earth: Environmental Sensing Technology and the Making of a Computational Planet. Minneapolis, MN: University of Minnesota Press.

Graham, S, and S. Marvin. 2001. Splintering Urbanism: Network Infrastructures, Technological Mobilities and the Urban Condition. London: Routledge.

Hollands, R. G. 2015. Critical Interventions into the Corporate Smart City. Cambridge Journal of Regions, Economy and Society 8 (1): 61-77. doi:10.1093/cjres/rsu011.

Howe, C., J. Lockrem, H. Appel, E. Hackett, D. Boyer, R. Hall, M. Schneider-Mayerson, A. Pope, A. Gupta, E. Rodwell, et al. 2016. Paradoxical Infrastructures: Ruins, Retrofit, and Risk. Science, Technology, \& Human Values 41 (3): 547-65. doi:10.1177/0162243915620017.

Isin, E, and E. Ruppert. 2015. Being Digital Citizens. London: Rowman \& Littlefield International. 
Joss, S., M. Cook, and Y. Dayot. 2017. Smart cities: Towards a new citizenship regime? A discourse analysis of the British smart city standard. Journal of Urban Technology 24 (4), 29-49. doi:10.1080/10630732.2017.1336027.

Karvonen, A., F. Cugurullo, and F. Caprotti, eds. 2018. Inside Smart Cities: Place, Politics and Urban Innovation. London: Routledge.

Kitchin, R., P. Cardullo, and C. Di Feliciantonio, 2019. Citizenship, justice, and the right to the smart city. In The Right to the Smart City, ed. R. Kitchin, P. Cardullo, and C. Di Feliciantonio, 1-24. Bingley, UK: Emerald.

Kooy, Michelle, and Karen Bakker. 2008. "Technologies of Government: Constituting Subjectivities, Spaces, and Infrastructures in Colonial and Contemporary Jakarta". International Journal of Urban and Regional Research 32 (2): 375-91. doi:10.1111/j.1468-2427.2008.00791.x. de Lange, M., and M. de Waal. 2013. Owning the City: New Media and Citizen Engagement in Urban Design. First Monday 18 (11). doi:10.5210/fm.v18i11.4954.

Lauermann, J. 2018. Municipal Statecraft: Revisiting the Geographies of the Entrepreneurial City. Progress in Human Geography 42 (2): 205-24. doi:10.1177/0309132516673240.

Maalsen, S., and S.-Y. Perng, 2017. Crafting code: Gender, coding and spatial hybridity in the events of PyLadies Dublin. In Craft Economies, eds. S. Luckman and N. Thomas, 223-232. London: Bloomsbury.

Maalsen, S., S. Burgoyne, and M. Tomitsch. 2018. Smart-innovative cities and the innovation economy: A qualitative analysis of local approaches to delivering smart urbanism in Australia. Journal of Design, Business \& Society 4 (1): 63-82. doi:10.1386/dbs.4.1.63 1.

Marvin, S., A. Luque-Ayala, and C. McFarlane, eds. 2016. Smart Urbanism: Utopian Vision or False Dawn. NY, USA: Routledge. 
Mattern, S. 2018. Maintenance and care. Places Journal. Available from: https://placesjournal.org/ article/maintenance-and-care/ (accessed 21 November 2018).

McLean, A., H. Bulkeley, and M. Crang. 2016. “Negotiating the Urban Smart Grid: Socio-Technical Experimentation in the City of Austin". Urban Studies 53 (15): 3246-63. doi:10.1177/0042098015612984.

Meehan, K. M. 2014. “Tool-Power: Water Infrastructure as Wellsprings of State Power". Geoforum 57 (November): 215-24. doi:10.1016/j.geoforum.2013.08.005.

Rossiter, N. 2017. Imperial Infrastructures and Asia beyond Asia: Data Centres, State Formation and the Territoriality of Logistical Media. The Fibreculture Journal 29: 1-20. doi: $10.15307 /$ fcj.29.220.2017

Roy, A. 2009. "Civic Governmentality: The Politics of Inclusion in Beirut and Mumbai". Antipode 41 (1): 159-79. doi:10.1111/j.1467-8330.2008.00660.x.

Silver, J. 2014. Incremental Infrastructures: Material Improvisation and Social Collaboration across Post-Colonial Accra. Urban Geography 35 (6): 788-804. doi:10.1080/02723638.2014.933605.

Shelton, T. 2018. Digital civics. In Digital Geographies, eds. J. Ash, R. Kitchin, and A. Leszczynski, 250-259. London: Sage.

Vanolo, A. 2016. Is There Anybody Out There? The Place and Role of Citizens in Tomorrow"s Smart Cities. Futures 82 (Supplement C): 26-36. doi:10.1016/j.futures.2016.05.010.

Viitanen, J, and R. Kingston. 2014. "Smart Cities and Green Growth: Outsourcing Democratic and Environmental Resilience to the Global Technology Sector". Environment and Planning A: Economy and Space 46 (4): 803-19. doi:10.1068/a46242. 
Von Schnitzler, A. 2008. “Citizenship Prepaid: Water, Calculability, and Techno-Politics in South Africa". Journal of Southern African Studies 34 (4): 899-917. doi:10.1080/03057070802456821. 